\title{
Interacción, público, multitud
}

\author{
Interaction, public and crowd
}

Joan Uribe Vilarrodona*

Citar este artículo como: Uribe Vilarrodona, J. (2019). Interacción, público, multitud.

Revista Nodo, 13(26), pp. 78-96

\section{Resumen}

El uso del espacio público conlleva de forma implícita la gestión del conflicto que en él se origina, muchas veces, en forma de emergencia (aquello que "emerge" de manera inesperada y que precisa de una especial intervención). La gestión de tales conflictos puede abordarse a título individual o colectivo; también puede gestionarse desde la configuración de la multitud. Su devenir, lejos de confirmar la presunta inconsistencia del pacto social confirma la vigencia y fuerza del mismo. La labilidad que implica forma parte de la argamasa que construye lo social, y los sistemas casi homeostáticos, de gestión y regulación del conflicto en el seno de la sociedad, así lo demuestran.

Palabras clave: Emergencia, interacción, conflicto, pacto social, espacio público

\section{Abstract}

The use of public space implies implicitly the management of the conflict that is originated in it, many times, as emergency (that which "emerges" unexpectedly and requires a special intervention). The management of such conflicts can be addressed individually or collectively; They can also be managed from the crowd. Its future, far from confirming the alleged inconsistency of the social order confirms its validity and strength. The lability that implies is part of the mortar that builds the society, and the almost homeostatic systems of conflict management and regulation within the social, demonstrate this.

Keywords: Emergency, interaction, conflict, social order, public space

\section{Introducción}

Este artículo es parte de una investigación más amplia realizada con el fin de explorar la producción de emergencias en el contexto del espacio público, concretamente aquellas de índole más supuestamente disruptiva y en las que los efectivos policiales se veían implicados. El objeto de dicha investigación fue explorar el orden social, en tanto que construcción social no establecida a nivel formal por institución ni concepción supraindividual alguna; examinar hasta qué punto puede estar compuesto por una amalgama de construcciones instantáneas y potencialmente cambiantes en función del contexto. También, se pretendió determinar hasta qué punto los acontecimientos sociales categorizados legalmente

Fecha de recepción: 15 julio de 2019 - Fecha de aceptación: 3 de agosto de 2019

* Doctor en Antropología Social, Universitat de Barcelona. Grup de Recerca en Exclusió i Control Social (GRECS) y Observatori d'Antropologia del Conflicte Urbà(OACU). Correo electrónico: joan.uribe@ub.edu 
como "delitos" suponen, o no, un elemento de crisis respecto al supuesto ordenamiento social.

La opción metodológica básica fue la observación no intrusiva, integrándome como un elemento más del entorno urbano en un ejercicio presencial en patrullajes policiales en tres ciudades de Catalunya: Barcelona, Hospitalet de Llobregat y Lloret de Mar. El trabajo de campo se llevó a cabo en un período de tres meses y la dinámica fue la de implicarse directamente en el espacio público, realizando una búsqueda activa y localización de hechos a partir de un mapeo previo de posibles entornos proclives (Barcelona); mientras que en las otras dos ciudades (Hospitalet de Llobregat y Lloret de Mar), se consiguió estar dentro de los coches policiales mientras patrullaban lo cual garantizó la aproximación al objeto de estudio, de difícil acceso en otros supuestos.

En relación con las herramientas metodológicas inspiradoras del trabajo, éstas fueron proporcionadas en gran medida por Lofland (1971) y (1984), una guía que hace referencia central a la observación no intrusiva y que perfila las potencialidades de esta herramienta cualitativa, facilitando pautas y recursos respecto a su aplicación metodológica. También fue de gran utilidad orientativa en lo que atañe a la técnica de la deambulación desde una perspectiva etnográfica, Colette Pètonnet con su texto clásico sobre la observación flotante (1982).

Otro trabajo de referencia fue el de Ryave y Schenkein (1974) sobre las prácticas peatonales en un determinado espacio público que ofrece orientaciones sobre el momento de realizar las observaciones en relación a si los individuos están detenidos o en marcha, solos o en grupo. Finalmente, el artículo de Wolf, "High risk methodology, reflections on leaving an outlaw society" (1991), que aborda la observación de aquello que está en el espacio de lo liminar y, por tanto, ofrece pautas para la gestión de esa complejidad desde la etnografía.

\section{El individuo enfrentado a la}

\section{emergencia}

Tomemos cada persona como unidad básica de observación y entendámosla también como unidad de interacción. Situémosla en el marco del espacio público urbano y observémosla a través de su circulación peatonal, es decir, como una unidad vehicular (Goffman, 1979, p. 25). Una persona que se desplaza por el espacio público al mismo tiempo que otra, que muchas otras, que una multitud de personas que se desplazan simultáneamente y de manera rutinaria (Joseph, 2002, p. 98). Persones que están solas, que, a pesar de estar rodeadas de otras, lo que hacen, el cómo hacen lo que hacen, el cuándo y por qué lo hacen puede no tener nada que ver con el resto de personas con las que coinciden en un mismo espacio y tiempo.

Sin embargo, a pesar de su consciente mutua inconexión con el resto es muy probable que si alguien en medio de una calle transitada chilla, una mayoría se detenga y busque con la vista el motivo del incidente; si alguien empieza a correr porque pierde el autobús, otros también lo hagan con el mismo objetivo; si dos miran una ventana de un edificio con cierto nerviosismo, muchos se añadan; si unos cuantos que andan en línea recta se apartan un poco a la derecha, como cuando hay un agujero en el suelo que se debe esquivar, muchos adopten preventivamente la misma actitud sin saber muy bien cuál es el motivo. Estas son evidencias de que, a pesar de estar solas, las personas que estamos en el espacio público en simultaneidad con otras conformamos con éstas un grupo social. Un grupo efímero, nunca cerrado, siempre cambiante, inestable $y$, de entrada, sin conciencia de serlo ni ánimo de acción común. Pero, como dice Tarde, es un grupo social en tanto que es una reunión de seres dispuestos a imitarse entre sí, o en tanto que, sin imitarse actualmente, se parecen y sus rasgos comunes son antiguas copias de un mismo modelo (1907, p. 95). Efectivamente, la multitud de personas, es decir, de unidades de interacción que coinciden y comparten un marco espacio temporal, constituyen por este solo hecho una 


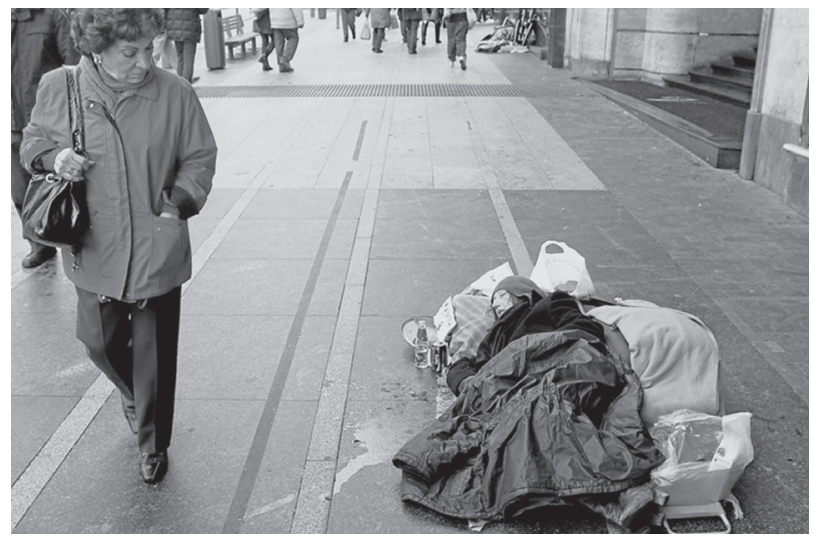

Figura 1. Durmiendo en la calle. Fuente: Ignacio Gil, 2018

fugaz, efímera y casual actividad que los confirma como grupo social.

Continuaremos por el momento con el individuo como unidad de interacción, es decir, como forma básica que dispone de múltiples modos de reacción ante lo que ocurre en el espacio público. Hablamos de la gente justamente para referirnos a este conglomerado disperso de personas que, solas, aunque rodeadas de otras que como ellas se transportan por las vías, observan constantemente a corta y media distancia lo que pasa ante sus ojos o a su alrededor en esa acción constante que Goffman llama ojeo (1979, p. 31). Lo hacen con el fin de recoger en todo momento la información necesaria que les permita establecer y modificar las tácticas de aproximación y superación de cuerpos, hechos, sorpresas, accidentes, contingencias que surgen en el camino, lugares considerados peligrosos pues, como dice Carrer, "cada uno de nosotros elabora, según la propia cultura, según la propia experiencia y percepciones, un mapa mental de sitios positivos y negativos, tranquilos y peligrosos, agradables y angustiosos que hay que frecuentar o que hay que evitar con cuidado" (2001, p. 66). De manera similar, Lofland anota que las personas adquirimos significados y patrones fruto del aprendizaje de los fenómenos urbanos y que éste va dirigido a gestionarnos de manera adecuada en el espacio público (1985, pp. 96-117).

La acumulación de experiencias en el tránsito por el espacio público es el que nos permite combinar la intención del flaneurismo que nos propone Baudelaire $(1985,2000)$ : itinerar descubriendo al vuelo lo que se nos brinda a la vista, sin más intención que la del puro disfrute, con la plena y dura recogida de información operativa válida para contar con una especie de fondo de información adecuada relativa a qué hacer ante determinadas situaciones excepcionales. Muchas veces, ante un acontecimiento ajeno punzante, como por ejemplo una agresión o un accidente, nos detenemos para recoger datos destinados a ampliar nuestra posibilidad de salir con éxito de una situación similar caso de que la viviésemos en primera persona: son aquellas interacciones que, lejos de suponer una pequeña variable en la trayectoria de nuestro itinerario, son bastante extraordinarias para nosotros como para que nos tomemos la molestia de atenderlas -observándolas durante la marcha, mirando incluso cuando hemos pasado de largo o deteniéndonos a observar -. Son emergencias de las que, más allá del interés morboso que puedan suscitar, queremos saber cómo las abordan aquellas personas que las padecen o que tratan de resolverlas, para disponer de esta información si en algún momento fuésemos personas afectadas; quizá para ver a los que la han provocado y así poder identificarlos en otro momento. Esta identificación se hace sobre la persona o personas causantes, pero también sobre el grupo al que presuponemos que pertenecen, a menudo objeto de marcas estigmatizadoras. También llegamos a conclusiones relativas al lugar donde el hecho se ha producido y si es posible o probable que se pueda repetir en el futuro, lo cual puede determinar nuestra predisposición a volver a pasar por allí.

Pero en nuestra constante recogida de información hacemos algo más que medir circunstancias, establecer estrategias y acumular conocimiento para afrontar o evitar emergencias en un futuro. Lo que también hacemos, constituidos en espontáneos jueces de la utilización adecuada del espacio público es, por una parte, disfrutar de hechos, de momentos que nos parezcan dignos de ello. No obstante, también dedicamos nuestra atención al entorno y las interacciones que observamos para 
ejercer el control, no políticamente institucionalizado, no siempre sujeto a normas ni a estructuras explícitas, aunque sí es formal en tanto que aceptado, tácitamente consensuado al menos en sus aspectos generales y tenazmente aplicado de forma habitual: de alguna manera evaluamos si estamos ante una conducta considerable como normal o no (Remy y Voyè, 1981, p. 21).

Cabe decir que el del riesgo es un matiz importante dado que, cuando lo hay, sólo nos sobreponemos a esta circunstancia ante emergencias muy graves y sobrecogedoras, y aún con eso, no siempre. De hecho y de manera general, tanto sea por la observación como por la intervención en una emergencia, será decisiva la valoración que hacemos en cada caso del riesgo que corremos para decidir si nos involucramos o no; valoración en la que intervienen factores como la gravedad de la misma, el nivel de violencia - física, verbal o ambiental - que suponga y, sobre todo, la distancia física a la que nos encontramos del hecho, elemento que será estratégico en el momento de, una vez recogida toda esta información, tomar la decisión de pasar de largo o de implicarse ${ }^{1}$.

Así, las personas evaluamos constantemente los acontecimientos que suceden en nuestro entorno inmediato e, incluso, según sea su gravedad, constatada o probable, tomamos posiciones relativas a ampliar la información, al igual que cuando lo hacemos para informarnos y ampliar conocimiento y, si entendiéramos que fuera necesario y

1 En noviembre de 2007 se produjo un hecho de notable repercusión pública. En un vagón de los ferrocarriles metropolitanos de Barcelona un chico insultó y agredió físicamente una viajera ecuatoriana, en un ataque de claras connotaciones racistas. Las cámaras de seguridad recogieron el incidente, así como la actitud pasiva de otro viajero que estaba sentado a poca distancia de donde se producía. Buena parte de la polémica pública se desplazó de la agresión en sí a la valoración ética de la pasividad de la tercera persona que fue testigo de los hechos. En general, las discusiones se centraban en qué hubiéramos hecho cada uno de nosotros en una situación similar. Una excelente ilustración no sólo de este tipo de cuestiones relativas a si intervenir o no en una emergencia, sino de la problemática que implica a nivel moral.

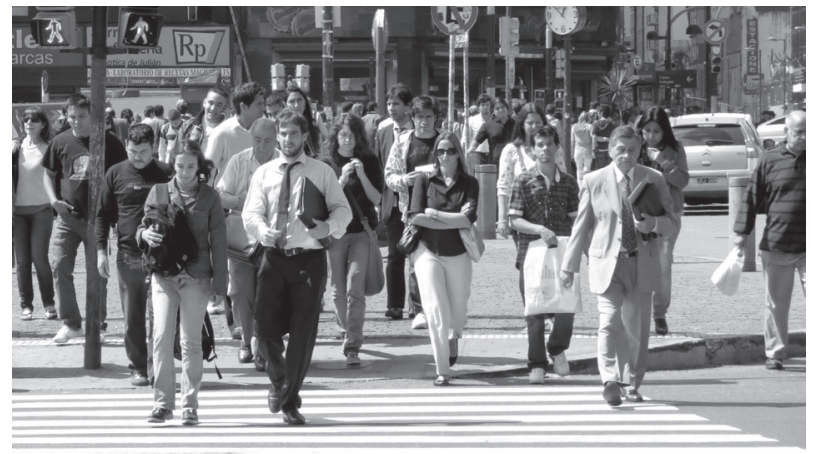

Figura 2. Danza callera. Fuente: https://1cruzdelsur.word press.com/2014/04/09/reflejos-e-instantes-en-la-calles-debuenos-aires

sintiéramos que podemos hacerlo sin ponernos en riesgo o, al menos, en uno que nos parezca crítico, participaríamos en el evento aplicando la forma de control que en ese caso se estime conveniente -llamar la atención de alguien, recriminar, detener algún hecho, reprimir alguna persona, reclamar de forma efectiva la presencia de la policía en forma de llamadas telefónicas, son algunas de las muchas maneras en que intervenimos aplicando control-, red espontánea de solidaridad en la que, en nombre de lo que esperaríamos que sucediera caso de ser nosotros los necesitados de apoyo, activamos mecanismos de apoyo de último momento, dirigidos no tanto a enderezar la causa de la emergencia en su sentido último, sino a detenerla y permitir la salvaguarda de los implicados y la posibilidad de seguir con inmediatez en su cotidianidad, siempre siguiendo la premisa de Tarde, según la cual lo que quiere la cosa social, sobre todo, es propagarse, no organizarse (Tarde, 1907, p. 100). Algunos ejemplos los tenemos en las personas que caminando sobrepasan el punto en que el joven que invoca a "Xesuchristo" hace gestos que se pueden llegar a considerar obscenos, se giran y le miran poniendo mala cara (Barcelona, 090301); o el hombre que, al sobrepasar una mujer que golpea con fuerza a sus dos hijos, a pesar de entender que la agresión no justifica su intervención, dice en voz alta: “ ¿Si les pega, ¿por qué va a buscarlos? " (Barcelona, 031201); las tres personas que al oír una alarma en un establecimiento cerrado, se detienen a unos cinco metros de la entrada y observan unos 
segundos, evaluando la posibilidad de un robo (Barcelona, 190301); o el vigilante de seguridad que llama por teléfono a la policía para avisar que un hombre un poco bebido deambula por la calle con dos barras de hierro (Hospitalet de Llobregat, 052504); o, por último, las personas que, desde una azotea, llaman la atención de los policías que están en la calle para decir hacia dónde ha huido una persona que están buscando (Hospitalet de Llobregat, 290504).

Estas personas solas ante las emergencias -físicamente solas o rodeadas de otras pero sin ningún vínculo concreto con ninguna de ellas- pueden ser testigos hasta su resolución, sin que sea necesaria su intervención; pueden volver a retomar su marcha, dejando de ejercer control visual y eludiendo la posibilidad de intervenir en auxilio de alguien o pueden acabar interviniendo en alguna de las formas del amplio abanico de posibilidades mencionado.

La intervención, en este caso, es un intercambio de apoyo (Goffman, 1979, pp. 78-79) sobre las personas a las que se asiste en el marco de la emergencia que padecen. Estos intercambios de apoyo se pueden dar también de forma simultánea a los que se establecen con otras personas solas y cercanas, todas ellas con un criterio y marco de actuación individual, a pesar de poder tener muchos otros individuos cerca, de forma que, en relación con el entorno de la emergencia, no puedan llegar a ser consideradas un público desde una lógica que, como nos dicen Remy y Voyé (1981, p. 22), estimula el individualismo en la vida cotidiana y tiende a evaluar negativamente todo lo que escape de este modelo.

Al finalizar el hecho y la interacción de apoyo, esta persona sola, todas las personas solas que viven en uno $\mathrm{u}$ otro momento una situación de este tipo, repasarán mentalmente los acontecimientos, procesarán la información sobre lo que han visto, lo que han hecho y cómo ha sucedido todo; a continuación almacenarán dichos datos para disponer de ellos en un futuro en forma de experiencia y conocimiento y volcarlos en otras interacciones en forma de invención, caso de que propongan una nueva forma de afrontar el hecho, invención basada en la combinación de su acumulación de experiencia y su capacidad creativa, o en forma de imitación, afrontando posibles situaciones similares a partir del modelo ya vivido y adaptándolo con los mínimos cambios necesarios en función de la nueva circunstancia.

\section{Las perfeccionadas posibilidades del público ante la emergencia}

Hasta ahora hemos hablado de nuestra unidad básica de observación, la persona, entendida como unidad de interacción y actuando de manera individual ante la emergencia. Pero existe la posibilidad de que ante una situación excepcional producida en el espacio público, las personas cercanas entre sí y que también muestren algún tipo de atracción en común hacia un mismo hecho que se produce en su entorno inmediato, constituyan un público, en el sentido utilizado por Tarde: son personas expertas en la práctica del hábito de la vida urbana y de la sugestión de la proximidad; que no se conocen entre ellas y, finalmente, que tienen un elemento de interés común, que es el que les da la característica de público común sobre aquello hacia lo que se interesan (1986, pp. 45-49).

Hablamos de un público que, como casi todo lo que acontece en el espacio público, es fugaz, momentáneo, cambiante, inestable y con objetivos concretos y breves, objetivos que una vez alcanzados o frustrados, darán paso a su disolución. Estas fusiones humanas momentáneas no deberán repetirse, al menos no con idénticas condiciones y características. Este estudio está repleto de ejemplos de entre los que quiero destacar tres: una detención en una acera de una amplia avenida de Hospitalet, muy cerca de una escuela y que provoca la concentración de decenas de personas, tanto niños como adultos (Hospitalet de Llobregat, 250504); la muchedumbre que se reúne mirando hacia arriba, embelesada a pesar del riesgo, bajo un edificio del que caen cosas por una ventana, 
arrojadas en el marco de una agresión en el ámbito familiar (Hospitalet de Llobregat, 060304), y, finalmente, la concurrida plaza donde se está llevando a cabo una identificación y posterior detención, en la que una cantidad notable de personas observa atenta los hechos y que, una vez han desaparecido de escena policías y detenidos, reaccionan como si despertaran de un sueño (Hospitalet de Llobregat, 050604).

El hecho de que las personas que realizan una actividad en solitario o con otras formando pequeños grupos se reúnan de golpe para constituir un público, que puede llegar a ser numeroso, es resultado de una serie de glosas corporales, aquellos gestos relativamente conscientes que sirven para que cada individuo brinde datos claros sobre sus predisposiciones inmediatas (Goffman, 1979, p. 139). A través de esta información podemos identificar personas que convergen con nuestros motivos de interés, en este caso una emergencia que se acaba de producir en un espacio urbano. El público en este caso es una red social ef ímera constituida por individuos que tienen una misma orientación perceptual y que están suficientemente cerca unos de otros como para poder ser distinguidos como unidad conductual -aquello que llamamos gente o gentío -. En algunas situaciones la unidad social sobrevenida puede limitarse a asistir como espectadora al evento que se está produciendo ante sus ojos, pero también puede aparecer predispuesta a ejecutar iniciativas conjuntas de intervención, como cuando ante un hombre de edad avanzada que parece está a punto de tocar de forma impertinente a una chica diciéndole "¡Ven niña, guapa, ven!", dos hombres intercambian miradas de apoyo mutuo y se ponen en disposición de actuar si fuera necesario, sabiéndose apoyados el uno en el otro (Barcelona, 031901).

Los elementos de estas glosas corporales pueden ser reconocimientos visuales, que permiten determinar qué están a punto de hacer las personas con las que se coincide; o verbales, indicando lo mismo, sólo que en voz alta. Estas señales, enviadas por personas individuales y recogidas por el resto de presentes, generan un campo gravitatorio específico de acción y comunicación que, en definitiva, sigue teniendo a su disposición posibilidades de reacción que tenían en un principio los individuos antes de constituirse en público, y que básicamente pasan por abandonarlo y continuar su camino, continuar en él asistiendo como testigo del suceso o intervenir, en el supuesto de que lo encuentre adecuado de acuerdo con determinadas circunstancias. Es lo que ocurre cuando las personas que pasan por la calle en ese momento, se quedan observando atentamente cómo tres individuos arrinconan a otros dos en el portal de un inmueble, pero que marchan al ver a un policía uniformado que se incorpora al pequeño drama que se está representando, poniendo de manifiesto al hacerlo que todo ello resulta de una actuación policial de paisano (Barcelona, 030901); o cómo al sobrepasar al invocador de "Xesuchristo" antes mencionado unos le ignoran, otros se giran y le sonríen y otros lo miran con reprobación (Barcelona, 090301); o aquellas personas que al asistir a la identificación de unos jóvenes cerca de una gasolinera una calurosa tarde de primavera en un polígono de Hospitalet, dejan de prestar atención y marchan a pocos segundos de empezar ésta, mientras otras se quedan observando (Hospitalet de Llobregat, 052404).

La intervención, caso de que llegue a darse, tiene un carácter colectivo y se auto organiza en el momento y sobre la marcha, generando una articulación espontánea. Como público la posibilidad de intervención es superior a la de las personas solas pues cada cual puede sentirse reforzado por el resto del grupo. Y su capacidad de incidir sobre la emergencia es superior en base a la suma y coordinación de energías concitadas.

\section{Personas: Animales públicos ${ }^{2}$ con intención de sobrevivir}

Hay una indiscutible dimensión espacial en la generación de sensaciones de inseguridad, como si el entorno que rodea una situación crítica o

2 Tomo el concepto de animal público de Manuel Delgado (1999). 
su posibilidad dependiera de elementos que, en la medida que son siempre de alguna forma dramáticos, deben ver reconocida la importancia del factor escenográfico. Las constantes alusiones al valor de la escena que se están haciendo a lo largo del presente estudio son la prueba. Esto conlleva la importancia que hay que concederle a lo que García (2002) llama, a través del título de su tesis doctoral, una ecología del orden público y de su mantenimiento. Cuando hablamos de ecología lo hacemos como uno de los elementos que reclamaba Radcliffe-Brown (1995, p. 12) para el estudio de los hechos sociales y que no es otra cosa que el nicho o entorno físico al que los individuos sociales deben amoldarse y que a su vez les moldea, y que pueden ser los elementos morfológicos más permanentes de un espacio colectivo -las fachadas de los edificios, los elementos del mobiliario urbano, los monumentos, etcétera-, así como también otros factores mudables, como la hora del día o de la noche, las condiciones climáticas, si el día es festivo o laboral, etc.; además, claro está, por la infinidad de eventos que suscita en todo momento la versatilidad de los usos -no pocas veces inopinados, como vemos que protagonizan los mismos peatones, todo ello conformando un ambiente cambiante, que funciona como una especie de pregnancia de formas sensible: visiones instantáneas, sonidos que irrumpen de repente o que son como un murmullo de fondo, olores, colores, que se organizan en configuraciones en parte estables, en parte en permanente mutación.

Son este tipo de perspectivas las que permiten atender las claves ambientales en la sensación de riesgo, incluso sin causas objetivas que la motiven, lo que podríamos llamar "estimación de vulnerabilidad". Aquí entran en juego factores como pueden ser los gradientes ausencia-presencia de otras personas -lo que nos permite comprender por qué en los espacios vacíos, solitarios, podemos agudizar el sentimiento de inseguridad, limpieza / suciedad, ruido / silencio, iluminación / oscuridad, familiaridad / desconocimiento, etc. Hay que mencionar trabajos al respecto que han hurgado en cómo esta percepción de inseguridad, dependiendo de factores más representacionales e imaginarios que no objetivos, se ha producido en contextos más cercanos a nosotros. Véanse las conclusiones de una investigación a propósito de las dimensiones psicológicas en la generación de "territorios del miedo", a partir del análisis de encuestas de victimización en la ciudad de Barcelona a principios de los años 80 (Lahosa,1989).

Este tipo de factores ambientales suscita verdaderos microclimas que están comprometidos no sólo en la sensación de seguridad o de inseguridad, sino también en las actitudes que las personas involucradas en ciertos acontecimientos aunque sea como meros testigos- reaccionen de una forma u otra. Por ejemplo, ¿qué activa el que personas solas o constituidas en un público, se interesen por una emergencia y, en algunos casos, lleguen a intervenir? Cualquier conclusión al respecto no puede ser cerrada ni concluyente, pues nos remite a un marco social sobremanera fluctuante. Sin embargo, Goffman nos da algunas pistas cuando nos dice que el primer filtro que propiciará o no el interés de la persona por un determinado hecho es la proyección de la vulnerabilidad que éste suponga para ella, es decir que si lo que capta es catalogado como con posibles o probables consecuencias sobre el universo social del que forma parte (Goffman, 1979, pp. 281-282; Joseph, 1982), si pone en crisis el ya de por sí frágil orden que le permite gestionar sus relaciones con los demás y con el mundo. Es aquí donde conviene remitirse al goffmaniano concepto de Umwelt (Goffman, 1979, p. 253), aquella región alrededor de la persona que permite detectar signos de alarma, un espacio de seguridad que varía en cada caso, región que funciona como una especie de burbuja de dimensiones y límites variables en función de cada contexto social y físico e incluso de cada orden cultural. La proxémica ha establecido que esta "burbuja" se hincha o deshincha en función del tipo de vínculo que cada individuo mantiene con los individuos con los que se encuentra: una distancia personal cercana, de cuarenta y cinco a setenta y cinco centímetros, en la que se tiene acceso físico fácil y directo hacia el otro; una distancia personal lejana, de los setenta 
y cinco a ciento veinte centímetros, donde se situaría el límite de la dominación física en sentido propio; una distancia social en fase cercana, de ciento veinte centímetros a dos metros, distancia en la que se tratan asuntos impersonales; y una distancia social en fase lejana, de dos a tres metros y medio, que posibilita un control del entorno así como poder seguir llevando a cabo tareas en presencia de otros sin parecer desatentos (Hall, 1999, pp. 143-159).

Todos estos factores condicionan reacciones diferentes en cada persona ante un mismo hecho, en función de la distancia a la que se esté produciendo y a partir de aquella en la que se percibe en riesgo. Al mismo tiempo explica por qué normalmente suelen pasar de largo las personas que en su deambular pasan a pocos metros o centímetros de una emergencia, mientras las que atraviesan a más distancia - por ejemplo, la acera contraria-, suelen detenerse. E incluso por qué se detienen más personas cuando esta circunstancia se da en una calle de aceras anchas que cuando es de aceras estrechas, donde un desarrollo imprevisto de los acontecimientos, podría ponerlas en peligro al disponer de menos tiempo y capacidad de reacción. Lo vemos en la reacción de las personas que están en una parada de autobús de las Ramblas de Barcelona y, al detenerse una furgoneta policial y acercarse sus ocupantes con paso decidido hacia unas personas que allí están, el resto de presentes a menos de dos metros, y por tanto en riesgo inme-

Goffman dice que las líneas de acecho son tres: detrás de la espalda, detrás de las separaciones -es decir, tras aquellos obstáculos físicos que no nos permiten ver más allá- y detrás de la oscuridad. diato, se separa rápidamente a una distancia que no en vano se da en llamar como "prudencial", mientras que los peatones que transcurren por el paseo central, se detienen a mirar (Barcelona, 031301); o en cómo, ante una mujer enloquecida que grita en medio de las Ramblas, concurridas de gente, nadie se detiene a mirarla de frente, pero varias personas lo hacen cuando la han sobrepasado y esta les da la espalda (Barcelona, 031901); o cómo al gritar unos adolescentes que juegan corriendo: “AAl ladrón, al ladrón!", refiriéndose a uno de ellos, los peatones cercanos al presunto ladrón siguen atentamente los hechos durante unos segundos, evaluando la escena, mientras los que están más lejos ignoran lo que pasa (Barcelona, 032301); o la detención antes mencionada en una avenida de Hospitalet de Llobregat, observada por una multitud de personas que se mantienen a cierta distancia, mientras que las que pasan por la acera donde se desarrolla el núcleo de la acción, a menos de cinco metros, siguen caminando como si no estuvieran interesadas en lo que acontece (Hospitalet de Llobregat, 052504); similar a cómo, en la calle Montseny de Hospitalet de Llobregat, relativamente estrecho, las personas que circulan por una acera se detienen a mirar cómo los policías hablan en la acera contraria con el propietario de un bar, mientras que aquellas que pasan por la misma, casi contactando físicamente con los protagonistas de la acción, pasan de largo, seguramente escuchando con atención, pero sin detenerse (Hospitalet de Llobregat, 05290); o los transeúntes que, según si están cerca o lejos de una identificación policial que se hace en la confluencia de las calles Riera Blanca y Santa Eulalia, se detienen a observar o siguen su camino sin detenerse (Hospitalet de Llobregat, 010604).

Además, Goffman nos señala que líneas de acecho (1979, p. 293) y puntos de acceso (p. 296) son categorías que sirven para designar los puntos críticos de nuestra Umwelt; dice que las líneas de acecho son tres: detrás de la espalda, detrás de las separaciones -es decir, tras aquellos obstáculos físicos que no nos permiten ver más allá- y detrás de la oscuridad. Carrer afirma al respecto que "es 
posible trazar unas características que pueden contribuir a crear un sentimiento de inseguridad: oscuridad, falta de visibilidad, ausencia de presencias positivas (...), etc." (2001, p. 66), y que "la inseguridad (...) está constituida, por una parte, por el riesgo objetivo de ser implicado en un acto de agresión, y por la otra por la percepción individual de este riesgo y de la evaluación de la propia vulnerabilidad personal "(p. 65). Encontrarnos con una emergencia en cualquiera de estos supuestos hace más difícil nuestra reacción voluntaria ante ella. Por otra parte, los puntos de acceso son todos aquellos por los que se puede acceder a nuestra Umwelt; la distancia corta, el ataque verbal o físico, la amenaza, son algunos ejemplos. De hecho, cualquier persona podría considerar a la policía en sí misma como un punto de acceso si alguna vez se siente interpelada y cuestionada ante un inesperado abordaje policial. Ejemplos de puntos de acceso recogidos en la investigación son el chico que camina solitario las 02:30 de la noche por una calle de Hospitalet cuando es interpelado por una patrulla sobre si ha visto a otra persona y reacciona con miedo, asustado, mudo, como bloqueado, hasta que se sobrepone y contesta (Hospitalet de Llobregat, 290504). O las personas que, controlando su miedo y sobreponiéndose al riesgo y la gravedad de los hechos, auxilian al chico apuñalado y la chica histérica en una calle extremadamente oscura e inhóspita, destacando entre ellas un hombre que, pálido, tembloroso, se esfuerza en explicar lo que ha pasado a los policías que aparecen repentinamente en el lugar (Hospitalet de Llobregat, 052804).

La combinación de estas circunstancias, siempre con la premisa de su relativa imprevisibilidad, de su diferente abordaje y resolución en cada caso, por similares que puedan parecer, es la que nos puede hacer entender estas diferentes "percepciones individuales" de una eventualidad emergente de las que nos habla Carrer. A modo de ejemplo se puede mencionar cómo ante un posible ataque verbal de contenido sexual de un hombre mayor a una chica muy joven, a pesar de poder tener una evidente incapacidad física para llegar a abor- darla de cualquier otra forma, se propiciará que se constituya de forma inmediata un público que, atendiendo a la presunta indefensión de la persona agredida, reprenda y silencie al agresor; mientras que el 27 de enero de 2001 un joven ecuatoriano, Wilson Pacheco, después de haber recibido una paliza y haber sido lanzado al mar, murió ahogado en medio de la negra noche junto a la pasarela de madera que une el centro comercial Maremagnum con las Ramblas de Barcelona sin que ninguna de las personas presentes en el lugar hiciera nada para salvarlo. De hecho, testigos presenciales que declararon en el juicio explicaron cómo intentaba agarrarse a una columna sin conseguirlo hasta desaparecer, sin que ninguno de ellos reaccionara. Otra testigo se mostraba sorprendida de que ningún vigilante presente se lanzase al agua para rescatarlo, sin cuestionarse porque ella misma no lo había hecho.

En uno y otro caso intervienen de forma decisiva la relación entre la percepción del riesgo que supone la intervención respecto a nuestra Umwelt, la oscuridad que implica la combinación de noche y mar, o el riesgo que implica el entorno físico del hecho -el frío, el medio acuático, el tenebroso ambiente del lugar y el momento- y el beneficio que nuestro riesgo puede suponer para otros. Respecto al miedo que sentimos, esta relación es la que decantará la balanza de nuestra actuación o bien hacia la disgregación, aislamiento y construcción de barreras que rompen el tejido social e imposibilitan la comunicación y la interacción de sus partes, o bien hacia la vinculación, la generación de nexos en torno a un sentimiento compartido de vulnerabilidad que reactualiza y potencia los acumulados sociales y culturales al alcance de los grupos sociales para garantizar la permanencia en contextos amenazados permanentemente con la alteración o disolución (Villa et al., 2003, p. 149).

Esta es una de las razones de la administración pública para organizar y planificar la presencia de especialistas en la custodia de nuestras Umwelt: los y las policías, presencia que la mayoría social interpreta como necesaria. Se espera que su formación cumpla la misión de garantizar el 


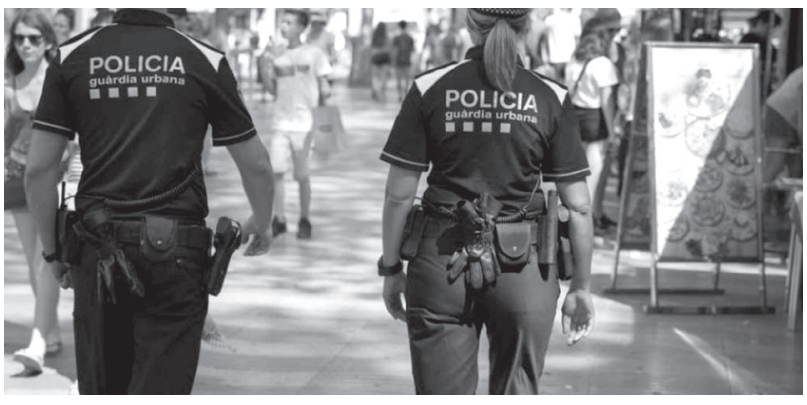

Figura 3. Guardia urbana en Las Ramblas. Fuente: https:// www.metropoliabierta.com/el-pulso-de-la-ciudad/sucesos/ guardia-urbana- operativo-raval_11702_102.html

mantenimiento o restablecer las Umwelt de las personas, sin tener en cuenta el riesgo que esta intervención pueda implicar para su propia. Esta circunstancia así como su entrenamiento para afrontar la emergencia, minimizando los riesgos para otros y para sí mismos, es lo que les da la categoría de especialistas y justifica las prerrogativas legales e instrumentales de las que se les dota para poder cumplir el objetivo. De hecho, eso es lo que transmiten al observador algunos de los miembros de la unidad policial con los que se patrulla en Lloret de Mar, agentes de policía con los que el investigador había patrullado años antes y en los que en el momento de la investigación se aprecia una serie de capacidades aprendidas que les permiten no dejarse llevar por las emociones, sin por ello dejar de ser empáticos, resolviendo las situaciones y gestionando, con auténtica habilidad y dominio, la energía humana que se les ofrece, en muchas ocasiones, desbocada (Lloret de Mar, 082202).

\section{La multitud: la temible condición silenciada del social en estado puro}

Retomo ahora a la persona como unidad de interacción, de la que ya hemos visto cómo puede reaccionar ante una emergencia de forma individual o como miembro de un público para pasar a otro modo de interacción, también en forma de grupo social especialmente constituido para la ocasión: la multitud, aquella entidad social en contraste de la cual surge -hay recordarloel concepto de público, oposición fundadora presentada por Dewey a principios de siglo XX y de forma precursora a Tarde (Dewey, 2004). La multitud se puede constituir a partir de una suma de individuos, de forma instantánea e imprevista incluso por sus miembros, como aparentemente ocurrió con la "manifestación tan popular como espontánea" de Caracas, el 27 de febrero de 1989 y que acabó con miles de personas muertas (Rotker, 2000, p. 217). También puede surgir fruto de la mutación, también espontánea, a partir de un público.

Como el público, la multitud lo es respecto a un hecho o intención comunes y es una entidad social por la fugaz pero intensa relación de cada uno de sus miembros con el conjunto de personas que se funden, conductores y multiplicadores de su energía, que, en relación al caso que nos afecta -el del surgimiento de emergencias- puede emprender actos concernientes al evento que lo ha hecho surgir de la nada. Es también el agrupamiento social más temido, más volátil, y el más rápido y radicalmente cambiante en muchos casos, porque, como dice Tarde, cuando forma parte de una multitud "el ser es poseído todo entero y arrebatado irresistiblemente por una fuerza sin contrapeso" (1986, p. 50). Nada o casi nada puede hacer la persona inmersa en la multitud caso de que en algún momento quiera desvincularse de la misma, más que intentar salir físicamente de ella, única manera de dejar de formar parte de la energía que lo alimenta y de estar nutriéndola con la propia, liberándose sólo en tanto que, en términos de distancia social, la persona es capaz de perder contacto con el grupo (Hall, 1999, p. 23). Y a causa de este arrebato y de esta fuerza irresistible, es de donde surge la intensidad de la multitud, pero también lo fácilmente manipulable que puede ser en determinadas circunstancias. El propio Tarde lo ejemplifica de forma casi poética cuando dice "entre la condena radical y la adoración, entre el horror y el entusiasmo, entre los gritos de 'que viva!' y 'que muera!', no hay término 
medio por una multitud: 'que viva!', quiere decir 'que viva para siempre.' Se presenta aquí un deseo de inmortalidad divina, el comienzo de una apoteosis. Pero es suficiente una insignificancia para cambiar la divinización en condenación eterna" (1986, p. 64). Un agente de policía viene a decir lo mismo con palabras sencillas en la puerta de una discoteca en la que se amontonan unas doscientas personas borrachas y excitadas, a las 03:15 horas cuando, al apostarse en la acera de frente, uniformado, orientado hacia el grupo en cuestión, dice: "es que la gente, a veces, salta una chispa y 'bum. Pero también puede ser muy borrega y sólo para vernos a los dos aquí, se quedan todos tranquilos..." (Lloret de Mar, 082202).

Es primordial reconocer en la multitud no sólo su componente social, sino también su esencia básica y fundamentalmente social: la multitud es sociedad en estado puro, como lo demuestra el hecho de que en una mayoría de multitudes, ninguna de las personas que la integran harían por sí solas lo que pueden llegar a hacer como muchedumbre. Sus acciones, pues, nacen de su condición de grupo social y fundamentalmente de ella o, como

\section{Es primordial reconocer en la multitud no sólo su componente social, sino también su esencia básica y fundamentalmente social: la multitud es sociedad en estado puro, como lo demuestra el hecho de que en una mayoría de multitudes, ninguna de las personas que la integran harían por sí solas lo que pueden llegar a hacer como muchedumbre.}

dice Delgado, "las multitudes son la materia prima de lo social moderno, al mismo tiempo que su componente diabólico larvado" (Delgado, 2001, p. 22).

No hay todavía planteada una antropología de las multitudes. Podrían establecerse sus bases a partir de los ensayos de análisis provistos por la sociología de los comportamientos colectivos, deudora de la ecología urbana, del interaccionismo simbólico y de las teorías de la acción social. Sus precursores ya asumieron a principios de siglo la necesidad de atender estos agregados sociales tan efímeros como poderosos, y hacerlo trascendiendo la estrechez de miras de la psicología social de la época. De este modo, los teóricos de la Escuela de Chicago intentaron enfrentarse al permanente estado de crisis que la multitud parecía experimentar, su tensión crónica, los inopinados movimientos de alarma, de euforia o de pánico que constantemente la agitaban y que, recordaban a Park la agitación de los mercados financieros, la actividad frenética de la bolsa. Desde el interaccionismo simbólico, a finales de los años 30 del pasado siglo, Blumer propuso una sistematización en el estudio de los fenómenos de masas que, entre sus tareas, asumió el estudio de conductas colectivas de signo hostil. Lejos de las servidumbres psicopatológicas, las actuaciones de las multitudes amotinadas comenzaron a ser tipificadas como "nuevas formas de interacción para afrontar y redefinir situaciones no estructuradas" (Smelser, 1995 [1963], p. 19). Este tipo de eventos violentos podían ser estudiados en función de lo que los interaccionistas llamaban "conductividad estructural", así como de otros factores, como son la tensión estructural, la existencia de creencias generalizadas o los factores dramáticos desencadenantes en relación a los cuales los murmullos, los, digamos, "ruidos de fondo", jugaban un papel determinante. Sin embargo, y sin desmerecer sus esfuerzos formalizadores, la sociología de las conductas colectivas nunca dejó de ver los furores masivos como disfunciones, resultantes a su vez de un debilitamiento del control social y del fracaso 
de las pautas culturales vigentes con vistas a hacer frente a cuadros de indeterminación. La acción de las masas se constituía así en una variable de desviación y desorganización sociales, una prueba de la naturaleza desestructurante de la vida urbana y la manifestación de una infantil búsqueda de soluciones elementales en situaciones de conflicto.

Poco se ha recorrido en el camino hacia una ciencia de las multitudes que, trascendiendo las insuficiencias de la historia y la sociología materialistas o del conductismo colectivo, fuera capaz de levantar un método de registro y de análisis que sepa desvelar en la actividad de las masas, -incluso cuando llega a cotas extremas de destructividadformas extremadamente complejas y eficientes de autogestión social. Por supuesto que no hay nada parecido a una etnología de las multitudes, una aplicación de la holística antropológica que tantas veces se ha antojado como una magnífica expresión de esta alteridad que suele proclamarse como su objeto central de conocimiento.

En la dirección de constituir esta antropología de la actividad multitudinaria pendiente, expresión de un interés más amplio por lo fractal, lo azaroso y el fluido de la vida social, no se podrá permanecer de espaldas a los intentos de la física actual para aplicar sus modelos explicativos en el campo de la sociodinámica. Es desde aquí que se abren nuevas perspectivas para lo que vendría a ser una suerte de etología de las multitudes. Las investigaciones en simulación computarizada de sociedades artificiales y en modelización de fuerzas sociales nos están ayudando a saber más sobre la coordinación automática e inconsciente que organiza los comportamientos colectivos humanos. Los experimentos informáticos con gente virtual han dado resultados interesantes en el caso las conductas fusionales de los seres humanos, aunque por ahora sólo en situaciones de pánico (Helbing, Farkas y Vicsek, 2000). En esta misma línea de buscar nuevas vías hacia la comprensión de la lógica de las multitudes, habrá que aprender algo -aunque sólo sea a título de su valor como metáfora - de lo que los teóricos de la termodinámica no lineal llaman comportamientos colectivos no triviales,

\section{Poco se ha recorrido en el camino hacia una ciencia de las multitudes que, trascendiendo las insuficiencias de la historia y la sociología materialistas o del conductismo colectivo, fuera capaz de levantar un método de registro y de análisis que sepa desvelar en la actividad de las masas.}

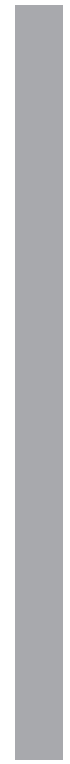

conductas ordenadas observables en ciertos sistemas lejos del equilibrio en el ámbito macroscópico - pese al aparente desorden microscópico de sus componentes moleculares-, que crecen hasta llegar a un cierto límite en su tamaño, para luego desaparecer. En cualquier caso, es desde la física de los sistemas complejos que las ciencias sociales interesadas por la actividad de las masas deberían asumir logros y analogías, precisamente como realización concreta de lo ya insinuado desde la primera ecología urbana, sobre todo para realzar las propiedades emergentes de la muchedumbre, sus virtudes como ejemplo de auto organización de unidades y sucesos.

La multitud, como reacción ante una emergencia, es, básicamente, un tribunal sumario que juzga sin juicio y ejecuta su propia sentencia. Un tribunal que más allá de la convención o norma actúa como ser social puro, libre de normas y convenciones, no sujeto a nada más que a la pulsión que en ese momento decida, de manera espontánea como grupo, quizás insinuada por algún de sus componentes y asumida por el resto, tal vez espontáneamente ejecutada. Se recogen algunos inquietantes ejemplos en la investigación, como cuando un grupo de siete hombres autóctonos de mediana edad, algunos de ellos bebidos, increpan a gritos y a pocos centímetros de distancia, en la 
negrura de la noche, a dos hombres latinoamericanos que, de manera estoica y seguramente atemorizada, aguantan hasta que llega la policía. Unos minutos antes, otro hombre latinoamericano que nada tenía que ver con estos había orinado en la vía pública provocando la indignación de los autóctonos e ignorándoles a continuación. Estos, reaccionan llamando a los dos que pasaban casualmente por allí. Algunos de los autóctonos dicen, a gritos: "¡Yo no tengo nada contra esta gente, yo no soy racista, pero tendrían que quemarlos a todos!". Estos respetables padres de familia y miembros de la comunidad, de no haber aparecido la policía, ¿habrían agredido a los hombres?, ¿les habrían golpeado?, ¿habrían intentado quemarles? (Hospitalet de Llobregat, 52904). Otro caso se da cuando las patrullas llegan a un requerimiento en el que se encuentran a Bekali, el joven marroquí demenciado que ha roto el cristal del escaparate del bar de unos ex-amigos suyos, y que está sentado en el suelo cubriéndose la cabeza herida con las manos, mientras los otros están de pie, a su alrededor. Según un testigo de la situación que explica los hechos a un agente de policía, los que lo rodeaban estaban "hechos unas fieras y le han arrinconado, y yo te juro que pensaba que se lo cargaban... Y al llegar vosotros han parado". Se estaba produciendo un intento de linchamiento (Hospitalet de Llobregat, 040604).

La multitud se constituye automáticamente, fusionada circunstancialmente con una intención más inmediata y menos elaborada que la del público, con acciones más brutales y menos sutiles que las del público (Tarde, 1986, pp. 72 -147). Cuando se auto constituye e interviene se puede tener por heroica, o por justa, por cruel, por brutal, por magnánima, por liberadora. Pero más allá de alcanzar o no los objetivos de este arrebato efímero, como grupo social en estado puro y liberado de toda norma, lo que hace de forma pavorosa es cuestionar un orden más o menos estable, más o menos continuo, poner en cuestión la idea de compromiso en el cumplimiento de la norma, pasando por encima de ella a cualquier precio y ante cualquier circunstancia. Al manifestarse, la multitud comunica que lo que hay, no es más que un grupo social dotado de personalidad propia en el que lo que no hay, es, justamente, personas con identidad, sino una única instancia con voluntad e inteligencia propias. Y no se debe perder de vista que, incluso cuando se manifiesta en forma de altercado, la multitud no niega la sociedad, sino que, al revés, muestra la capacidad que ésta tiene para reclamar la violencia como recurso (Rosset, 1994).

La multitud es, además, con toda probabilidad, injusta, pues su intención y motivación no es la de hacer justicia, cuando menos en el sentido más institucional del término, pese a que llegue a esgrimirse a veces como argumento, bajo la forma de lo que suele presentarse como justicia popular: su objetivo último es el de ejercer su energía, focalizada sobre algo o alguien, muchas veces por lo que representa y no por lo que es o por lo que ha hecho, por lo que es prácticamente imposible que se aplique con justicia sobre esa persona u objeto. De ahí los linchamientos, como ejemplo de una forma de manifestación de la multitud, que pueden ser interpretados más como el síntoma de una circunstancia preocupante por el grupo, que decide solucionar la cuestión por la vía más rápida, como si la muchedumbre tuviera el derecho y la virtud de ejercer formas radicales de urgencia social. De ahí que podamos contemplar la actividad multitudinaria como la entrega a un espasmo que libera lo que se considera una justa medida correctora sobre hechos concretos o determinados supuestos contraventores.

Por todo ello, la policía, la responsable de la guarda y custodia de las Umwelt y también del orden constituido en el orden de lo cotidiano tal como aparece regulado en el marco legal, responde en general de manera muy rápida, con dedicación y medios especiales, pero también con cierto nerviosismo ante las multitudes. Las multitudes son, ante todo, imprevisibles, a menudo devastadoras y potencialmente brutales, como demuestran ejemplos extremos como el linchamiento ilustrado fotográficamente de un presunto 
colaborador del régimen depuesto en Haití, que es pateado, lapidado, mutilado y quemado vivo, todo públicamente ${ }^{3}$; o el linchamiento en Yenín de un palestino presuntamente colaborador de los israelitas, que es tiroteado y pateado en la calle, mientras la multitud increpa el cadáver y lo fotografía con los teléfonos móviles, simbolizando de esta manera la buena acogida y legitimación popular del presunto acto de justicia ${ }^{4}$; o el linchamiento de dos policías mexicanos no uniformados, a quien unos delincuentes, para librarse de su vigilancia, hicieron confundir con secuestradores de niños y que durante cuatro horas y pese a la oposición de algunas personas, son golpeados durante horas, atados, arrastrados, pinchados, cortados y, finalmente, quemados vivos entre risas y bromas, sin que el hecho de ser entrevistados por la televisión mientras estaban siendo torturados y asesinados lograra apaciguar los ánimos ${ }^{5}$.

Así pues, los policías se activan ante uno de los síntomas de la posible generación de una multitud, siempre capaz de desencadenar formas intensísimas de energía social. Hablamos de concentraciones espontáneas de personas, que además se muestran físicamente bastante activas o con tendencia a hacerlo. Pero esto no es una multitud, sino un público, en la medida que la agrupación la conforman personas que no han renunciado a su individualidad autoconsciente y no han llegado todavía al estado de fusión psicológica que caracteriza una masa (Joseph, 2002, pp. 70-76). Ellos lo saben; pero la acechan. Con prudencia y con la desazón de no colaborar ellos mismos a activar una multitud a partir de un público, sobre excitado su energía y provocando el estallido imprevisto (Tarde, 1986, p. 58). Por eso el jefe de turno envía una patrulla de paisano, consciente de la importancia de evitar la presencia del uniforme, a observar algo que, de hecho, no es ningún delito ni es un problema de seguridad ciudadana, pero que teme que pueda llegar a

\footnotetext{
3 El Periódico, viernes, 5 de marzo de 2004, p. 18

4 El Periódico, lunes, 14 de agosto de 2006, p. 12.

5 El País, jueves, 25 de noviembre de 2004, p. 8.
}

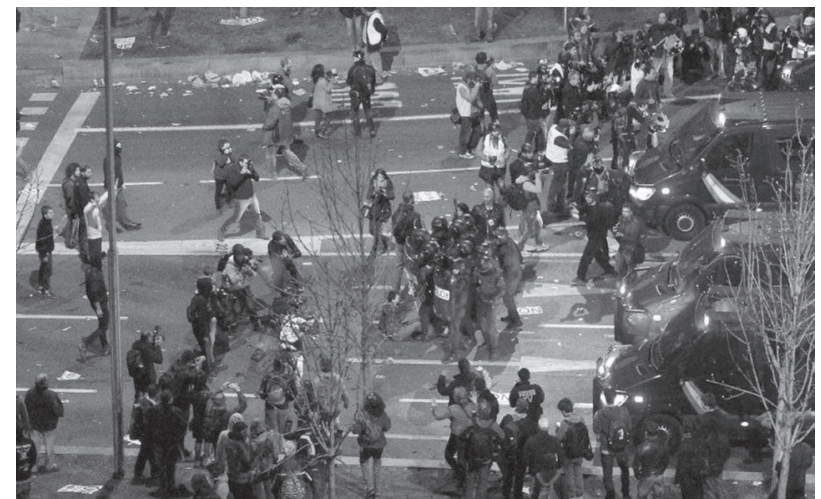

Figura 4. Disturbios urbanos. Fuente: https://www.lainformacion.com/files/article_main/uploads/2017/09/22/59c4a29 19bd83.jpeg

serlo: un grupo de personas que, reivindicativas, impiden el inicio de las obras a una construcción por un problema de ruidos. Y los envía para que de forma prudente y discreta y sin excitar los ánimos de aquel grupo, estudien y evalúen la posibilidad de que se convierta en multitud en un momento dado (Hospitalet de Llobregat, 240504).

La multitud, sin embargo, es más cosas, y los policías lo saben. Para la policía, la multitud tiene un rastro incluso sensorial -la tensión de los gritos, los sonidos derivados de sus actos, a veces incluso los olores, el movimiento espasmódico, tenso e intenso de sus miembros-, y posee formas específicas de abordaje. A partir de la premisa de su posible ductilidad, a veces se desactiva tan inmediatamente como se ha activado sorprendiéndola brutalmente: un sonido anormal, una carga inesperada de la policía, a veces dos policías solitarios atacando el centro de una multitud, pueden ser, por el efecto sorpresa, suficiente para disolverla. Es lo que hacen los dos policías que viendo a distancia que han de intervenir solos sobre una multitud excitada y agresiva, corren decididos hacia ella gritando y alzando las defensas, haciendo que ésta se abra ante ellos debido a su decisión y, al estar en el centro de la misma, con actitud firme, verbal y actitudinalmente agresiva, consiguen desactivarla. Y por eso cuando un rato después una parte del público se quiere reactivar como multitud para iniciar un posible linchamiento, otra vez la actitud 
decidida es suficiente para apaciguar instantáneamente los ánimos (Lloret de Mar, 082402). O que otra multitud excitada en una calle estrecha se calme ante la visión de los técnicos sanitarios de la ambulancia que, con una actitud tranquila, atienden a unos heridos (Lloret de Mar, 082202).

A veces hay que dejar que la multitud ejecute su acción cuando se la considera imparable o cuando intentar detenerla pueda suponer un daño superior al que puede estar llevando a cabo. En cualquier caso, la multitud es un organismo vivo, es la sublimación elevada a la máxima intensidad de la dimensión social de la vida urbana que, curiosamente, se manifiesta desde un aparente caos y parece liberar energía de forma indiscriminada, para sacudir y cuestionar, para negar y abolir todo lo que está establecido, en orden a lograr objetivos inmediatos que se le antojan adecuados y perentorios. A veces creativa, festiva y liberadora. $Y$ en otras ocasiones fascinante y temible, brutal, incontenible y espontánea, imprevisible, seguramente arbitraria muchas veces si se la contempla desde la perspectiva de la moral individual. Es posible que esta sea la forma más apasionante - por apasionada- de la sociedad urbana moderna, con lo que se podría coincidir con las intuiciones de ciertos teóricos de la multitud de finales del siglo XIX (Moscovici, 1985, pp. 98-136), descontando aquellos que, desde la psicología de masas, le atribuyeron a las muchedumbres las cualidades de irracionalidad o locura colectiva (Le Bon, 1986). Tarde dice que la multitud es el grupo social del pasado (1986, p. 49) y parece querer apuntar que es un tipo de asociación que debe caducar y dejar de tener sentido ya en su época, a finales del siglo XIX, de la mano de los públicos, que pasarían a ocupar su lugar, canalizando sus potencias en un sentido más orgánico y menos descontrolado. No es así. Es cierto que se han intentado diversas y astutas estrategias de canalización de las energías colectivas para transformarlas en público: por ejemplo, en forma de estados de opinión, corrientes de pensamiento, modos, afiliaciones, tendencias culturales muy monitorizadas, puntos de concentración o de flujos muy controlados así como acotaciones espaciales que facilitan el control, tales como grandes superficies comerciales, espacios temáticos, eventos de masas, muchos de ellos en estadios deportivos, en referencia a los que no quiero dejar de citar a Body-Gendrot, quien dice que no es casual que en los estadios de fútbol se dé un clima permanente de inseguridad y de violencia, ya que éstos son unos de los pocos espacios donde se permiten o toleran las manifestaciones desatadas de las emociones colectivas, los desbordamientos verbales, gestuales, a menudo políticamente "incorrectos", como los de signo xenófobo o los asociados a ideologías totalitarias (1995, p. 169).

En otro orden de cosas, determinadas corrientes del urbanismo y la arquitectura al servicio del miedo intentan no canalizar, sino separar, y lo hacen definiendo un modelo de ciudad en el que la segregación espacial de las actividades tiene un papel importante, ya sea en forma de barrios privados o semi privados; de espacios para la educación de los jóvenes de acceso restringido (Lofland, 1985, p. 67), por poner algunos ejemplos, y que son la muestra de una especialización del espacio destinada a agrupar por afinidades o intereses y descartar sistemáticamente al otro innecesario en ese momento y contexto. O se intenta operativizar este control y separación del otro o de los otros, con propuestas que supuestamente deberían propiciar la homogeneidad social y la imagen de un centro seguro, de la que este texto recogido por Davis es un ejemplo:

Se puede diseñar el centro para hacer sentir a sus visitantes que, en su totalidad o en una parte significativa, es un lugar agradable y la clase de lugar que a las 'personas decentes' las gusta frecuentar [...] Un centro que sea compacto, con una gran densidad de desarrollo y multifuncional, concentrará a la gente, proporcionándole más actividades [...] Las actividades que se ofrezcan en esta zona determinarán el "tipo" de gente que paseará por sus aceras: situar oficinas u hogares de clase media y alta cerca del centro garantizará un elevado porcentaje de peatones "decentes", respetuosos de la ley. Una zona renovada de 
forma tan atractiva debe ser lo suficientemente grande como para determinar la imagen de conjunto del centro de la ciudad (2003, p. 202).

Con estas estrategias se consigue, por una parte, conducir mejor los flujos; Davis habla de cómo la nueva programación del downtown de Los Ángeles, procurando un flujo continuo de ocio, trabajo y consumo de clase media, ha acabado con la heterogeneidad de la zona, con el objetivo no de "destruir la calle", sino de "destruir la multitud" (Davis, 2003, p. 201)-y por otra, docilizar y prever mejor sus reacciones, intenciones y capacidades.

Pero seguramente la multitud es atemporal dado que es, sencillamente, el grupo social en estado puro que ejecuta una especie de instinto no menos colectivo; una especie de escritura automática de la sociedad que, por la energía que activa, puede resultar a la vez creativa y desoladora. Me remito a las palabras de Delgado cuando dice que:

la violencia de las multitudes no deja de tener, como se ha pretendido, un fuerte factor instintivo. Pero este instinto del que las masas son instrumento, no es un instinto animal, sino un instinto social e histórico. Si asusta, es por qué su aspecto brutal escapa de una ética a la que es del todo indiferente, pues aquella masa, por decirlo de algún modo, siempre "va a lo suyo". Parece que si la violencia de masas desconcierta es por qué la damos por irracional, pero en realidad es por qué preocupa que la falta de compasión que tantas veces aplica sea secretamente lógica, es más, porque tal vez sea una forma superior de racionalidad la que la masa ejerce, una racionalidad que está más allá de la moral y de las pobres razones con la política y sus juegos intentan redimirla (2001, p. 20).

La multitud, activada como reacción a una emergencia, se convertirá en muchos casos en emergencia por sí misma, pudiendo llegar a superar en magnitud a aquella que ha propiciado su gestación. En algún momento se desactivará: cuando alcance su propósito o se disuelva por su propia inercia o por la intervención de la policía, muchas veces a través de agentes especializados en el control sobre masas, los antidisturbios, cuya función es desvanecer grumos o cuajos humanos indisciplinados.

Hemos hecho un recorrido por los caminos que las personas, las unidades de interacción básica, pueden tomar ante una emergencia: la ignorancia de la misma, conformando parte del decorado que acompaña la existencia de un hecho de cierta relevancia en un momento y lugar concreto; su implicación, ya sea como testigos, ya sea participando de alguna forma en la corrección de los hechos que ocurren y rompen con lo cotidiano, ya sea aliándose con otras personas y ejecutando las mismas acciones, ya sea en forma de público -constituido por tanto por personas privadas que no pierden de vista su singularidad -, o entregándose a la muchedumbre que, con vida propia, intervendrá de manera no siempre previsible y pocas veces controlable, reparando la cotidianidad alterada o conduciéndola a su más desoladora exasperación.

\section{Conclusiones}

La incontestabilidad de la emergencia. Los casos recogidos y analizados abordan la incontestabilidad de la emergencia y, de su mano, la constatación de la fragilidad del pacto social. Pero las emergencias no sólo ponen en cuestión la estabilidad de cualquier orden social sino que, al mismo tiempo, hacen patente el esfuerzo de las personas para mantenerlo, la forma en que son conscientes de la responsabilidad que permanentemente asumen para garantizarlo y mantenerlo por encima de una imaginaria línea de flotación, permanentemente amenazada por todo tipo de sacudidas de las que irrupciones-interrupciones a las que esta investigación se consagra son una expresión radical. Es esta conciencia que los individuos tienen de hasta qué punto todo depende de que se amolden a colaborar en el mantenimiento del orden público, en el sentido tan goffmaniano de orden de las relaciones en público y en el sentido habitual que la ley establece de mantenimiento de la "tranquilidad ciudadana". Es así que el espacio urbano se convierte no sólo una producción, como 
estableció Lefebvre, sino en una coproducción, en la que podemos hacer alguna cosa más que transportarnos de un lugar a otro, sino un escenario "de confianza" en el que desarrollar actividad social y personal.

Orden público, orden institucional, y pacto social. Como dice Joseph "Goffman se centra más respecto a las relaciones de poder en el estudio del orden público que en el del orden institucional, y en las interacciones entre personas que no se conocen más que en las relaciones entre miembros de una misma comunidad" (1999, p. 72). De hecho, esta observación guarda relación con una de las críticas que históricamente se ha hecho a Goffman, basada en que, supuestamente, habría ignorado en sus textos el abordaje de la cuestión del orden. No fue así y es pertinente el matiz de Joseph, haciendo notar que la dimensión de la orden que captó el interés de Goffman es la del orden público, entendido como aquel nacido de las relaciones de control recíproco entre los individuos copresentes, dejando de lado el orden institucional, no porque no lo considerara de interés, sino sencillamente porque pensaba que se trataba de un asunto bastante tratado desde la macrosociología.

De hecho, se constata aquí la "trampa" de los sistemas legales que, como el español, recogen a través del ordenamiento jurídico que las fuerzas policiales tienen el deber de "garantizar" la seguridad ciudadana. La orden es clara, pero implica, como decíamos, una trampa, dado que nadie puede garantizar la seguridad: sencillamente, no es posible. Sólo lo sería, quizá, en sociedades reducidas y absolutamente panópticas, con más controladores que controlados, o en aquellas instituciones totales a las que Goffman dedicará un conocido ensayo, sociedades los miembros de las que viven integrados de forma absoluta en la vida del organización y ningún aspecto de su existencia escapa al escrutinio fiscalizador, a la manera de las cárceles, las escuelas internas, los cuarteles, los hospitales, los psiquiátricos, etc. $\mathrm{Y}$ a pesar de ello, ninguno de estos modelos de sociedad cerrada y sometida a hiper vigilancia podría asegurar nunca del todo que no se producirán a su sí deserciones, desacatos, desviaciones, transgresiones o desobediencias.

Pero, ¿Qué poder institucional está dispuesto a educar a las sociedades que administra en la evidencia de que la seguridad ciudadana se puede ampliar o mejorar, pero nunca "garantizar"? Uno de los rasgos que caracterizan a nuestra sociedad es la aceptación por parte de sus miembros que formar parte implica renunciar a cuotas de participación y acción en numerosos ámbitos fundamentales de nuestra vida -la seguridad, la salud, el mantenimiento de los objetos que nos rodean- y que esto supone una ganancia absoluto si la delegación a favor de mecanismos públicos institucionalizados y designados como competentes para hacerlo. En este contexto, ¿cuántas personas están preparadas para asumir una realidad a partir de la cual resulta que nadie puede garantizarnos y afrontar la vida en sociedad con la misma seguridad y confianza en sí mismos que tenían antes de asimilarlo? ¿Qué reajustes implicaría en las relaciones entre el individuo y el poder institucional? Queda, sin embargo, la sensación de que esta realidad es una constatación por parte de la mayoría. Que nunca se reconoce en voz alta, pero que se exterioriza a través de la renuncia que hacemos en favor de los mecanismos que nos ayudan a sobrevivir a los peligros que nos acechan.

El poder institucional, por otra parte, otorga derechos a los cuerpos policiales -derecho a la velocidad, el acceso a lugares y personas, a la interpelación, instalación, a la territorialización restrictiva del espacio-. Lo hace preocupado de que no parezca que, efectivamente, la fractura social es muchas veces imprevisible, irrevocable y puede quedar impune. Al mismo tiempo, también habría que preguntarse si realmente a los individuos no nos corresponde asumir más cuota de compromiso para con el riesgo propio o de otros, en nombre del pacto de ayuda mutua que todos firmamos de manera implícita -y no siempre cumplimos- o en nombre de lo que se considere en cada momento y en cada contexto que es bien común. 


\section{Referencias bibliográficas}

Baudelaire, Ch., (1985) El Spleen de París. Madrid: Club Internacional del Libro.

- (2000) El pintor de la vida moderna. Murcia: Colegio oficial de aparejadores y arquitectos técnicos.

Body-Gendrot, S., (1995) Villeet violence. Lirruption de nouveaux acteurs. París: PUF.

Carrer, F., (2001) "Seguretat i espai urbà". En: Revista Catalana de Seguretat Pública. Barcelona: núm. 9, desembre 2001, Escola de Policia de Catalunya, pp. 65-85.

Davis, M., (2003) Ciudad de cuarzo. Arqueología del futuro en Los Ángeles. Madrid: Lengua de trapo.

Delgado, M., (1999) El animal público. Barcelona: Anagrama.

- (2001) Luces iconoclastas. Anticlericalismo, espacio y ritual en la España contemporánea. Barcelona: Ariel.

Dewey, J., (2004) La opinión pública y sus problemas. Madrid: Morata.

García Sánchez, P. J. (2002) Formes et conflits d'urbanité à Caracas. Enquête sur l'écologie de l'ordre public. París: École des Hautes Études en Sciences Sociales, Tesis doctoral inédita.

Goffman, E. (1979) Relaciones en público. Microestudios del orden público. Madrid: Alianza.

Hall, E.T., (1999) La dimensión oculta. México: Siglo XXI.

Helbing, D.; Farkas, I.; Vicsek, I. (2000) "Simulating dynamical features of escape panic", Nature, 407, pp. 487-490.

Joseph, I., (1982) "L'analyse de situation dans le courant interaccioniste." Ethnologie française, XII/2 (1982), pp. 228-234.

- (1999) Erving Goffman y la microsociología. Barcelona: Gedisa.
- (2002) El transeúnte y el espacio urbano. Barcelona: Gedisa.

Lahosa, J. M. (1989) “Los territorios del miedo". En: Prevenció, 3 (diciembre 1989), pp. 76-85.

Le Bon, G., (1986) Psicología de las masas. Madrid: Morata.

Lofland, J., (1971) Analyzing Social Settings. A Guide to Qualitative Observation and Analysis. Belmont, California: Wadsworth Publishing Company.

Lofland, J.; Lofland, L. H., (1984) Analyzing Social Settings. A Guide to Qualitative Observation and Analysis. Belmont, California: Wadsworth Inc.

Lofland, L. H., (1985) A world of strangers. Order and action in urban públic space. Illinois: Waveland Press.

Moscovici, S., (1985) La era de las multitudes. Un tratado histórico de la psicología de las masas. México DF: FCE.

Park, R.E. (1995) "La ciudad, sugerencias para la investigación del comportamiento humano en el medio urbano". En: La ciudad. Barcelona: Serbal.

Pettonet, C., (1982) "L'Observation flottante", L'Homme, París, XXII/4, pp. 37-47.

Radcliffe-Brown, R., (1995) Estructura y función en la sociedad primitiva. Barcelona: Península.

Rèmy, J.; Voyé, L., (1981) Ville, ordre et violence. Formes spatiales et transaction sociale. París: PUF.

Rosset, C., (1994) El principio de crueldad. Valencia: Pre-textos.

Rotker, S., (2000) "Nosotros somos los otros". En: Ciudadanías del miedo. Caracas: Nueva Sociedad, pp. 217-229.

Ryave, A.L.; Schenkein, J.N., (1974) "Notes of the art of walking”. En: Ethnometodology, Turner, R. Middlesex: Penguin. 
Smelser, N.J. (1995) [1963] Teoría del comportamiento colectivo. México DF: FCE.

Tarde, G., (1986) La opinión y la multitud. Madrid: Taurus.

- (1907) Las Leyes de la Imitación. Madrid: Daniel Jorro, Editor.
Villa, M.I., et al., (2003) Rostros del miedo. Una investigación sobre los miedos sociales urbanos. Medellín: Corporación Región.

Wolf, D.R., (1991) "High Risk Methodology, Reflections on Leaving an Outlaw Society", En: Shaffir, W.B. i Stebbins, R.A., Experiencing Fieldwork an inside view of qualitative research. New York: Sage, 1991: pp. 211-223. 